\title{
Performance Evaluation of an Induction Motor Drive for Traction Application
}

\author{
Lino Di Leonardo \\ Department of Industrial and Information Engineering and \\ Economics \\ University of L'Aquila \\ L'Aquila \\ lino.dileonardo@univaq.it \\ Giuseppe Fabri \\ Department of Industrial and Information Engineering and \\ Economics \\ University of L'Aquila \\ L'Aquila \\ giuseppe.fabri@univaq.it
}

\author{
Mircea Popescu \\ Motor Design Ltd. \\ Wrexham, United Kingdom \\ mircea.popescu@motor-design.com
}

\author{
Marco Tursini \\ Department of Industrial and Information Engineering and \\ Economics \\ University of L'Aquila \\ L'Aquila \\ marco.tursini@univaq.it
}

\begin{abstract}
This paper concerns the design of an induction motor drive for traction application in the framework of the $\mathbf{E U}$ H2020 "Smart, Green and Integrated Transport" challenge. The target vehicle reflects the specification of a high-class electric vehicle, and it led to design a traction induction motor capable to provide $200 \mathrm{~kW}$ in the range from 6000 to $20000 \mathrm{rpm}$. The paper focuses on the performance evaluation of the motor design accounting for the drive control strategy. Design features and data are provided. Maximum performance both in the constant torque and the flux weakening zones are outlined by finite element method steady-state analyses, providing the thermal and supply limits. Then, the drive control is taken into account by dynamic simulations. The performance are evaluated over the whole torque-speed region considering the actual control strategy and driving modes of modern smart vehicles. Operating examples are provided.
\end{abstract}

Keywords - Electric traction, Induction motors, Finite element analysis, Electromagnetic transients, Motor drives, Control strategies

\section{INTRODUCTION}

In the automotive industry, the more realistically vehicle performance forecasting before prototyping is increasingly important to save time and costs, [1][2]. Particular attention is paid to the traction unit for obvious reasons.

The Induction Motor (IM) represents one of the most interesting alternatives for electric traction, as widely discussed in literature and implemented in remarkable actual solutions [1]-[7]. In particular, one of the most appreciated features of this machine is its ability to work at high speeds. In fact, the motor flux can be continuously controlled by the $d$-current component and then the speed range can be safely extended by field-weakening to over two time the nominal speed [8]. Indeed, the torque-speed mechanical characteristic curve of the field oriented controlled induction motor can be associated to the curves of the separately excited DC motor, particularly suited for traction.
Generally, the stationary equivalent electrical circuit of the IM is used to calculate the torque/speed characteristics and the starting features at fixed supply. The equivalent circuit parameters, namely stator and rotor resistances and leakage inductances and magnetizing inductance, can be measured by no-load and locked rotor tests [9][10]. With these parameters, dynamic models can be arranged too. However, the measurement tests can be done only after the prototype is realized. Moreover, due to the simplification of the model, this methodology presents inaccurate results when variable supply and operating conditions are involved. Particularly, high power density motors for traction are designed for maximum utilization of core iron at base torque/speed. Then, a relevant change of the saturation conditions is expected at flux-weakening or, generally, when the flux level is changed to pursue optimizing control strategies.

In this context, Finite Elements Method (FEM) analysis is becoming increasingly important for the design of electric motors in general including induction motors [11]. This typology of analysis allows to take into account important effects such as saturation as well as assessing transient aspects. The most famous software houses offer different types of electromagnetic analysis [12]. The power supply can be set in current or in voltage. By means of co-simulation analysis, the control strategies can be interfaced with FEM analysis of electric motors even if the calculation times can grow considerably [13]. This approach makes possible to evaluate the transient performance of the motor when it is driven by an inverter and there are speed and current feedback. The simulation may take longer to be tuned, but once fixed-up it allows to have a more accurate estimate of the whole drive system and to evaluate the performance in a new perspective [14].

This article concerns an induction motor drive designed for traction of a Battery Electric Vehicle (BEV) equipped with a couple of $200 \mathrm{~kW}$ electric motors (Premium vehicles). The goal of the study is the performance evaluation accounting for the drive field-oriented control strategy, [15]. 
Motor design features and data are provided. The performance are evaluated by targeted FEM computations and dynamic simulations over the whole torque-speed region considering the actual control strategy and the driving modes of modern smart vehicles, such eco, cruise, or sport modes. Operating examples are provided.

Section II presents the requirements of the high-class electric vehicle and the basic features of the designed IM. Section III reports the maximum steady-state performance of the motor calculated using the FEM software in both ranges, constant-torque and flux-weakening ranges. Section IV refers to the field-oriented control scheme and control strategies related issues. Finally, simulation results of typical operating modes are presented and discussed in Section V.

\section{VEHICLE REQUIREMENTS AND IM DESIGN}

The design of electric motors for BEV involves different aspects related to the vehicle performance, powertrain architecture and production. Premium vehicles are required to exhibit high maximum speed and fast accelerations for market acceptance. Moreover, BEV in premium class are affected by high weight due in part to the chassis and in part to the battery mass. The usual powertrain configuration in premium vehicles features two motor, one per axle, directly connected to the wheel by mean of a fixed reduction gear and the needed differential gearbox. The lack of a variable speed gearbox imposes the mechanical characteristics of the electric motor directly from the vehicle Force-Speed requirements. Additional important features of the motor-drive for BEV application is high efficiency and low weight because it has a direct impact on the battery sizing and related cost [16]. To enhance the specific power and specific torque of the motordrive high operating speed is preferred. Considering that the higher the operating speed the higher the complexity of the reduction gear and bearings, with impact on its efficiency, motor with speed over $20 \mathrm{krpm}$ are challenging to be integrated at reasonable cost.

The main reference requirements and the target mechanical characteristics for a motor-drive for the reference premium BEV are reported respectively in TABLE I and in Fig. 1,

TABLE I - REFERENCE REQUIREMENTS FOR PREMIUM BEV

\begin{tabular}{|r|c|c|}
\hline Weight & $(\mathrm{kg})$ & 2000 \\
\hline Acceleration 0-100km/h & $(\mathrm{s})$ & 4.5 \\
\hline Acceleration 90-120km/h & $(\mathrm{s})$ & 5.5 \\
\hline Peak Power & $(\mathrm{kW})$ & 200 \\
\hline Rated Power (30 min) & $(\mathrm{kW})$ & 70 \\
\hline Maximum speed & $(\mathrm{km} / \mathrm{h})$ & 230 \\
\hline Power @ Maximum speed & $(\mathrm{kW})$ & 60 \\
\hline Motor weight & $(\mathrm{kg})$ & $<40$ \\
\hline Motor efficiency (average on WLTP3 $)$ & $(\%)$ & 94 \\
\hline Max motor speed & $(\mathrm{rpm})$ & 20000 \\
\hline Battery voltage & $(\mathrm{V})$ & 800 \\
\hline Maximum phase current & $(\mathrm{Arms})$ & 500 \\
\hline
\end{tabular}

Three different areas characterize the motor torque-speed operation in BEV application (Fig. 1):

1) Accelerating area: high peak torque is required up to $120 \mathrm{~km} / \mathrm{h}$ to accelerate the vehicle, usually this performance is needed for few seconds (maximum 30s). The motor operates in strong saturation and high thermal stress. The motor performance is limited by the maximum current density in the windings and power converter current ratings.

2) Efficiency area: the most used region during driving and cruising in urban and extraurban driving cycle, the motor must guarantee the highest possible efficiency. Standard driving cycles (i.e. WLTP) for consumption estimation usually fall in this region.

3) High speed area: high speeds are required for German highway and for market penetration, the vehicle power needs to counteract the aerodynamic friction and highway slope. Usually for premium BEV $120 \mathrm{~kW} /$ motor are enough for $5 \%$ slope at $230 \mathrm{~km} / \mathrm{h}$. The motor operates in strong field weakening and with high frequency currents, performances are limited by the available DC voltage.

The requested torque at the base speed of $6000 \mathrm{rpm}$ is $320 \mathrm{Nm}$, while at the maximum speed of $20000 \mathrm{rpm}$ is $35 \mathrm{Nm}$ (points $\mathrm{P}_{\mathrm{A}}^{\text {spec }}$ and $\mathrm{P}_{\mathrm{B}}^{\text {spec }}$ in Fig. 1, respectively).

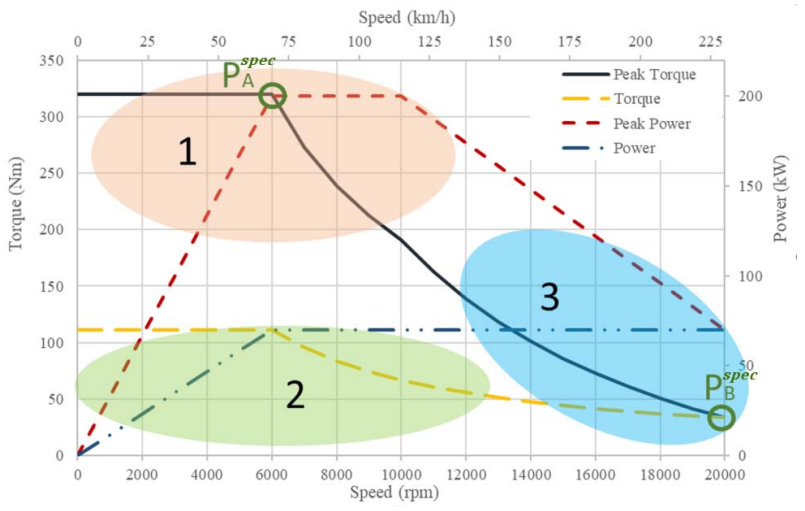

Fig. 1 Operating torque-speed zones of a motor-drive for premium BEV application

The proposed solution aims to obtain high specific power and torque (target values are $5 \mathrm{~kW} / \mathrm{kg}$ and $9 \mathrm{Nm} / \mathrm{kg}$ ). In particular, copper rotor die-casting and hairpin stator windings (higher slot fill factor respect to the wire windings) will be used. The motor is also designed for high speed operations: an optimization in term of iron, AC copper losses and mechanical losses has been carried out to reach the target efficiency. The design process outlines a motor configuration with 2 pole pairs, 36 stator slots and 4 hairpin windings for slot ( $73 \%$ copper slot fill factor). The rotor presents 50 closed bars in die-cast copper (Cu-ETP). The selected electrical steel is M235-35A which provides a good compromise between cost and losses at the working frequencies. The cross section and the main dimensions are shown in Fig. 2. The phases are star-connected with coils in series, the phase resistance of the hairpin windings calculated for the $70 \mathrm{~kW}$ working-point at base speed is $0.01703 \Omega$ at $135^{\circ} \mathrm{C}$.

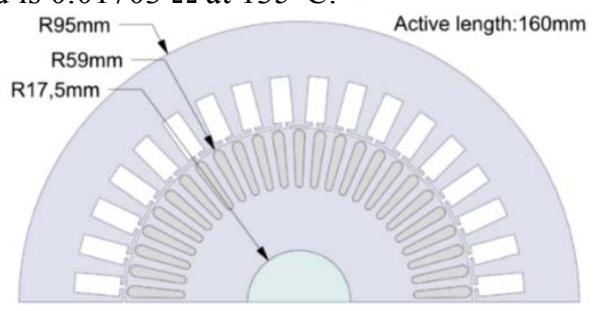

Fig. 2 Cross section and main dimensions of the traction IM 


\section{SteAdy-STATE PERFORMANCE REPORT}

By FEM software (standalone), steady-state performance are evaluated and the mechanical curve (maximum torque versus speed) are estimated. Ideal 3-phase sinusoidal currents are applied to the stator windings and the phase voltage are computed. The voltage feeding limit is considered, equal to $385 \mathrm{~V}_{\mathrm{pk}}$. This value has been computed considering the ideal sinusoidal feeding voltage of an inverter fed by an $800 \mathrm{~V} \mathrm{DC}$ bus (rated value) reduced of about the $16 \%$ to take into account the fluctuation of the DC bus below its rated and the inverter internal voltage drops.

Until base speed, it is possible to consider a constant-flux control strategy in order to keep the motor's torque capability constant. In this region the torque limit is imposed by the maximum thermal load (500 Arms phase current for $30 \mathrm{~s}$ ) and the maximum value of current that can be supplied by the battery and power converter. Fig. 3 shows different mechanical characteristics (blue curves) changing frequency of supplied current (with same amplitude) and the relative requested phase voltages (magenta) in constant-flux region. The voltage is always lower than the limit (red dashed line) imposed by the DC bus, so the maximum current is permitted and the maximum torque (green dashed line) is constant for every speed.

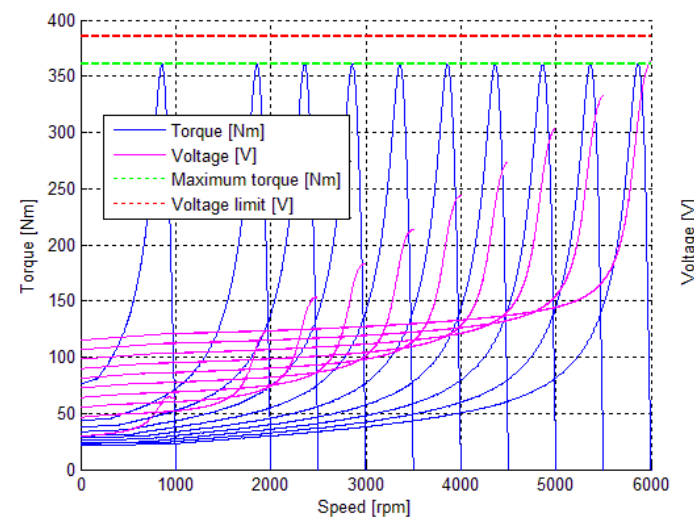

Fig. 3 Mechanical characteristics (blue curves), requested phase voltage (magenta curves), maximum torque (green dashed line) and voltage limit (red dashed line) in the constant-flux zone

In flux weakening, the voltage limit decreases the torque capability as speed increases. The weakening zone can be subdivided into two sub-areas respect to the speed.

In the $1^{\text {st }}$ sub-area (at speeds just above the nominal speed), the imposed current remains the nominal one used also for the curves in the constant-flux zone, but the slip is increased and the work points are not at maximum torque per current. In Fig. 4 the mechanical characteristics are represented for three different speed in the $1^{\text {st }}$ sub-area and the voltage limit (red crosses on the red line) defines the slip and the maximum torque for every speed (green circles).

In the $2^{\text {nd }}$ sub-area (where the maximum torque per frequency is possible for acceptable current values) the current amplitude is reduced respect to the base one to obtain a voltage value compatible with the limit imposed by DC bus. In Fig. 5 the mechanical characteristics refer to five different speeds in the $2^{\text {nd }}$ sub-area and the maximum values decrease in proportion of the supplied current amplitude. The work points (green circles) on the mechanical characteristics are also defined by the voltage limit (red line), as in the first subarea.

By steady-state simulations, the torque at the base speed of $6000 \mathrm{rpm}$ is $370 \mathrm{Nm}$, with a current of 498 Arms and a slip of 0.02334; while at the maximum speed of $20000 \mathrm{rpm}$ the torque is about $70 \mathrm{Nm}$ with a current of 283 Arms and a slip value of 0.01532 . These two design point are referred to as $\mathrm{P}_{\mathrm{A}}$ and $\mathrm{P}_{\mathrm{B}}$ in the following.

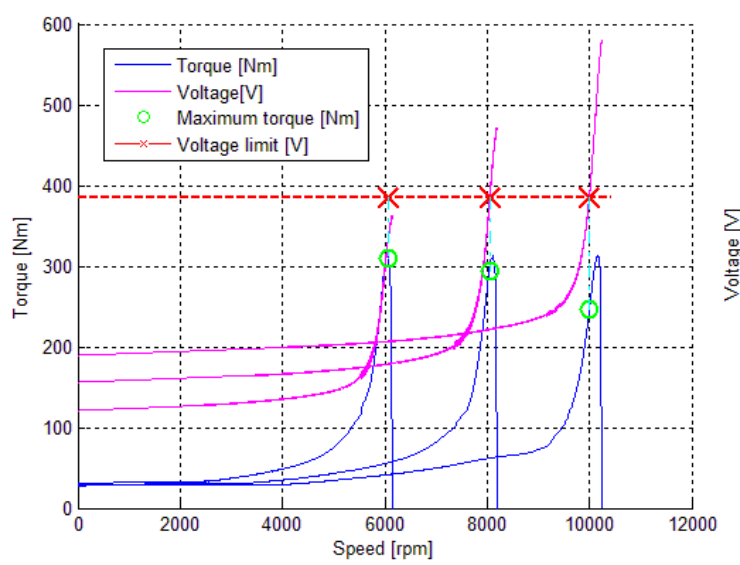

Fig. 4 Mechanical characteristics (blue curves), requested phase voltage (magenta curves), torque working points (green cirles) and voltage limit (red dashed line and crosses) in the $1^{\text {st }}$ flux-weakening zone

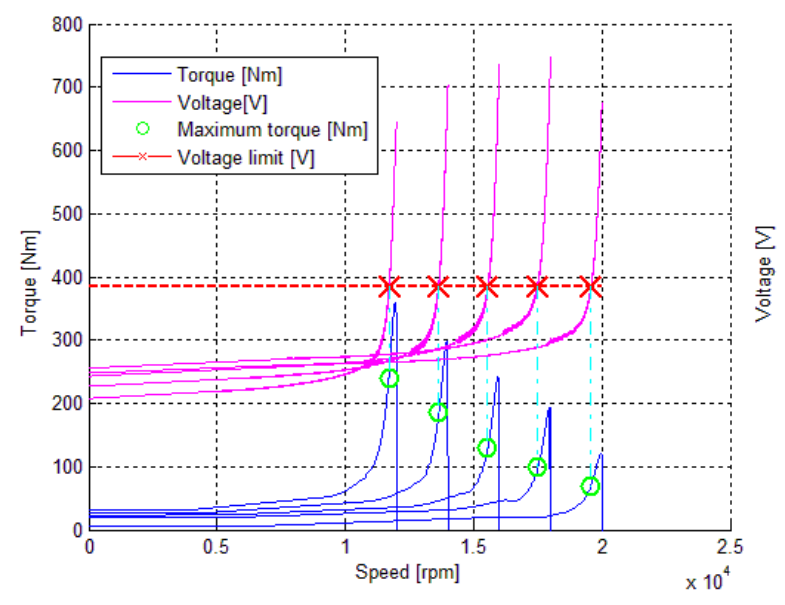

Fig. 5 Mechanical characteristics (blue curves), requested phase voltage (magenta curves), torque working points (green cirles) and voltage limit (red dashed line and crosses) in the $2^{\text {nd }}$ flux-weakening zone

\section{CONTROL Issues}

\section{A. Field Oriented Control}

Field-oriented control of IM allows to separate the components of the stator current responsible for the production of flux and torque, thus allowing fast and linear mechanical responses. Based on these components, different control strategies can be considered accounting for the thermal and supply limits of the motor drive.

In the reference frame $d-q$ aligned with the rotor flux linkage (see Fig. 6) the following relations apply by wellestablished literature: 


$$
\begin{gathered}
\psi_{r}=\int \frac{1}{T_{r}}\left(M i_{s d}-\psi_{r}\right) d t \\
\omega_{s l}=\frac{M}{T_{r}} \frac{i_{s q}}{\psi_{r}} \\
\theta(t)=\int \omega d t=\int_{M^{2}}\left(\omega_{s l}+\omega_{r}\right) d t \\
T_{e}=\frac{3}{2} p \frac{M^{2}}{L_{r}} i_{m r} i_{s q}
\end{gathered}
$$

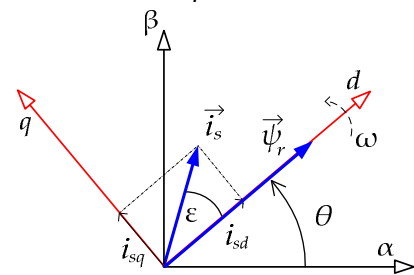

Fig. 6. $d-q$ reference aligned with the IM rotor flux

where the "rotor magnetizing current" $i_{m r}=\psi_{r} / M$ is defined for convenience, and:

$\psi_{r}, \theta$ rotor flux linkage amplitude and phase angle; $i_{s d}$ and $i_{s q}$ stator current $\mathrm{d}-\mathrm{q}$ components; $\omega_{r}$ rotor speed; $\omega$ synchronous speed; $\omega_{s l}$ slip speed; $T_{e}$ electromagnetic torque; $M$ magnetizing inductance; $T_{r}$ rotor time constant.

Equations (1), (2), and (3) give the so-called "rotor flux model in field coordinates", which can be used in a closed loop arrangement for a basic implementation of the Rotor Flux Oriented (vector) Control (RFOC) of the induction machine. The accuracy of this method strongly depends upon the proper setting of the rotor time constant $T_{r}$ and magnetizing inductance $M$, hence an adaptation engine is needed for these parameters, [10]. In fact, the rotor resistance varies with the temperature of the rotor windings and the magnetizing inductance with the flux level. The availability of reliable analysis tools such as FEMs allows to take into account the saturation effects, which are usually important in high power-density designs.

\section{B. Optimum control strategies}

When the rotor flux steady-state is established, equation (1) reduces to $\psi_{r}=M i_{s d}$, i.e. $i_{s d}=i_{m r}$. In these assumptions, the voltage and current operating limits and the constant torque loci (4) can be represented in the $i_{m r}-i_{s q}$ currents plane, they are ellipse, circle, and hyperbola shaped, respectively [17]. These loci can be correctly evaluated once the saturation effects are accounted: Fig. 7 shows their behaviour for the considered IM, traced assuming variable frequency and torque, and fixed voltage and current limits. The voltage limit ellipses collapse toward the axes center at increasing frequency.

The optimization criteria of the IM refer to maximum torque/current and maximum torque/frequency, and each of these strategies corresponds to a given curve on the $i_{s d}-i_{m r}$ currents plane: the maximum torque/current (MTPA) curve is the locus of the points closest to the origin over each constant torque hyperbola; the maximum torque/frequency (MTPHz) curve is the locus of the points at maximum torque over each voltage ellipse. The MTPA and MTPHz curves are shown in Fig. 7 for the IM considered in this paper. The design point $\mathrm{P}_{\mathrm{A}}$ at base speed, $6000 \mathrm{rpm}$, falls on the MTPA curve and the design point $\mathrm{P}_{\mathrm{B}}$ at max flux-weakening speed, $20000 \mathrm{rpm}$, falls on the MTPHz curve. The voltage limits are also traced considering the maximum available (phase) voltage of $385 \mathrm{~V}_{\mathrm{pk}}$. The base design point $\mathrm{P}_{\mathrm{A}}$ is reachable up to $239 \mathrm{~Hz}$, while the design point $\mathrm{P}_{\mathrm{B}}$ at flux weakening is reachable up to $678 \mathrm{~Hz}$.

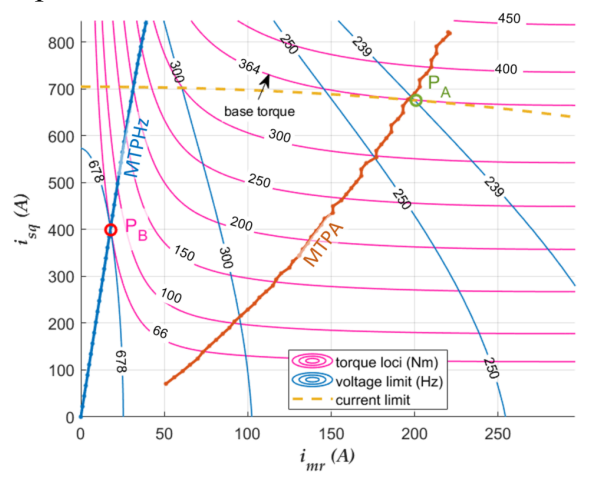

Fig. 7. Operating limits, torque loci, and optimization curves vs. IM design points (with voltage limit set to $385 \mathrm{~V}_{\mathrm{pk}}$ )

Maximum efficiency must be also considered, which allows to optimize the driving mode of the BEV (see Section II). To this purpose, speed-dependent efficiency maps in the $i_{m r}-i_{s q}$ plane can be evaluated, which are represented in Figures 8 and 9 and for the considered IM, respectively at driving (6000) and high speed (16000) rpm, compared with the MTPA curve and the constant torque loci. It is evident that the MTPA curve can be assumed for maximum efficiency in practical extents, as long as it comply with voltage limit at high speed.

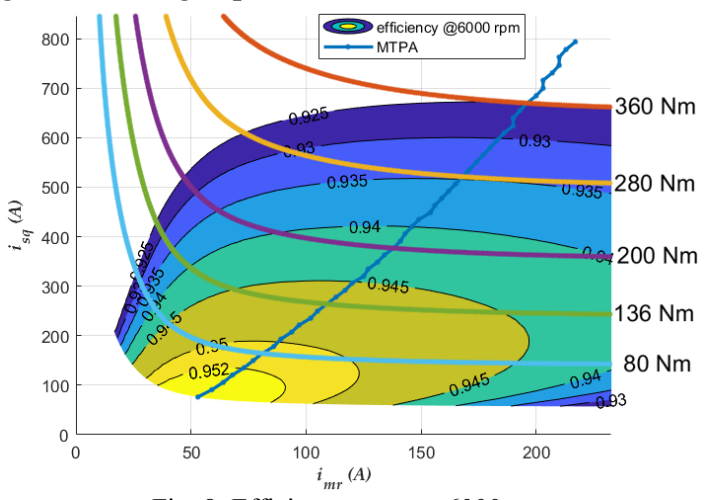

Fig. 8. Efficiency maps at $6000 \mathrm{rpm}$

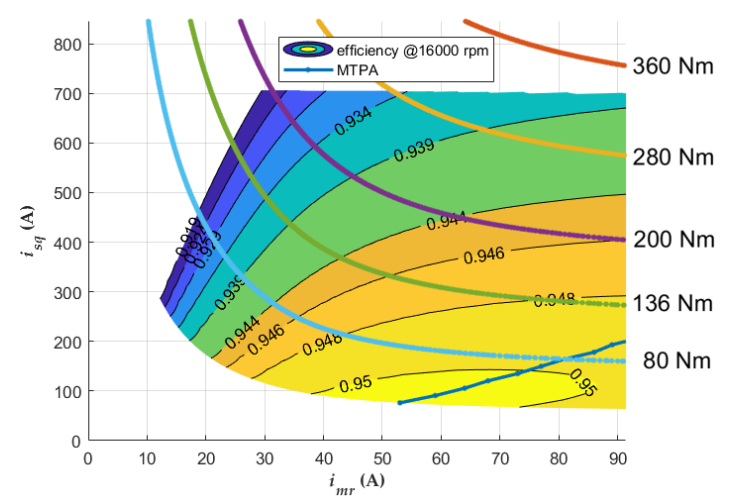

Fig. 9. Efficiency maps at $16000 \mathrm{rpm}$ 


\section{Control implementation and scheme}

The set-up of the overall control strategy of a field-oriented IM must account at least a couple of further items: first, constant rotor flux operation is desirable to improve the dynamic response of the drive at variable load; second, a minimum value of the rotor flux is appropriate to allow for its safe estimation.

Thereafter, the control of the traction IM is implemented as shown in Fig. 10. The rotor magnetizing current of the fluxweakening design point $\mathrm{P}_{\mathrm{B}}$ is set as minimum value. In the following, point $\mathrm{P}_{1}$ is that point on the MTPA curve having the same minimum rotor flux value.
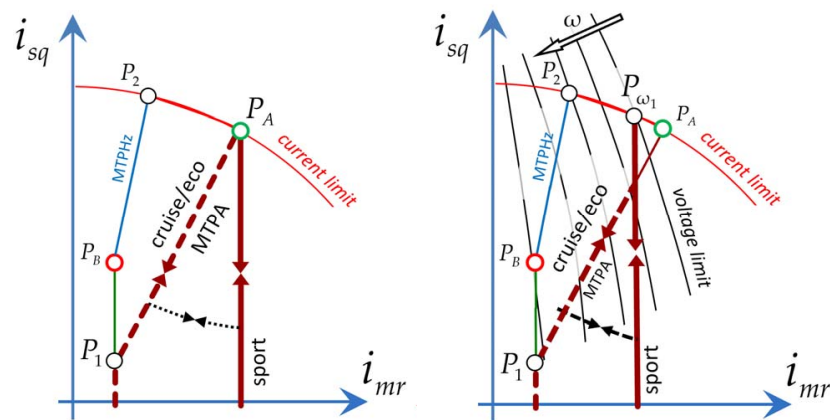

Fig. 10. Control modes in the constant torque (left) and flux-weakening (right) regions

For frequencies less than or equal to the base value (constant torque region), constant flux operation at base value is set when the sport mode is activated, while in eco mode the operation is controlled over the MTPA locus; maximum torque is achieved at the base design point $\mathrm{P}_{\mathrm{A}}$, where the IM will operate to satisfy most of the BEV acceleration performance. Above the base frequency, the operating zone is limited by the voltage limit ellipses and the base current circle, and maximum torque is achieved moving on the current circle at increasing frequencies ( $1^{\text {st }}$ flux weakening zone). The set point of the magnetizing current is reduced to comply with the voltage limit according to the point $\mathrm{P}_{\omega}$ in Fig. 10 and when the MTPHz locus is reached at point $\mathrm{P}_{2}$ the point $\mathrm{P} \omega$ is moved on this locus ( $2^{\text {nd }}$ flux weakening zone).

In speed controlled driving modes (cruise control), maximum efficiency operation may be suitably activated both in the constant-torque and in the flux weakening region: on-line algorithms or off-line, pre-computed frequencydependent trajectories can be implemented to this purpose.

The outer speed and flux loops of the field-oriented control scheme which implements the described control strategy is shown in Fig. 11. For any given operating condition, the $i_{m r}$ and $i_{s q}$ current references are calculated on the selected frequency-dependent control trajectory according to the torque command (block "OP calc.") and the selected driving mode.

\section{Simulation RESUlts}

Dynamic simulation has been arranged in Matlab/Simulink to evaluate the effects of drive control on the IM performance. The control scheme reproduces the structure in Fig. 11 apart for the flux regulator, which is omitted (i.e. $i_{s d}^{*}=i_{m r}^{*}$ ), while the rotor flux-oriented current control loops are included. Ideal SVPWM inverter is assumed and discrete control algorithm with 100 us sampling time. The IM is simulated by the lumped parameters model achieved by FEM analysis, accounting for the saturation of the magnetizing inductance.

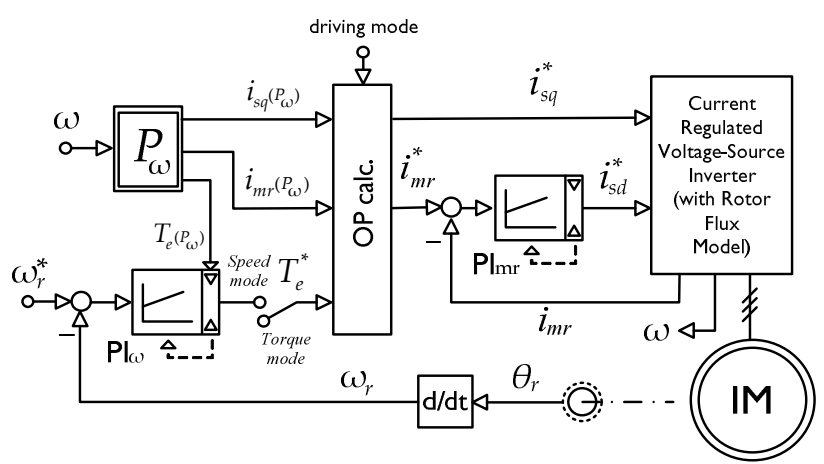

Fig. 11. Speed and flux control loops with flux-weakening

Figures from 12 to 15 present a transient from zero to $20000 \mathrm{rpm}$ speed with maximum acceleration and following steady-state at $1 / 2$ of the $P_{B}$ torque. This test was carried out in order to verify the feasibility of the maximum torque-speed capability by the control strategy described in the previous section. Just the motor inertia (and not the equivalent one of the $\mathrm{BEV}$ ) has been considered, in order to minimize the simulation time.

Fig. 12 shows the $d-q$ and the magnetizing currents vs. time. The magnetizing current $i_{m r}$ is commanded with a little advance respect to the $q$-current for safe initialization of the flux estimator, its delay respect to the $d$-current is clearly visible, due to the rotor time constant. Fig. 13 shows the polar plot of the currents, confirming that they are controlled on the $\mathrm{P}_{\mathrm{A}}-\mathrm{P}_{2}-\mathrm{P}_{\mathrm{B}}$ trajectory of maximum torque production. The delay of the magnetizing current is still more evident.

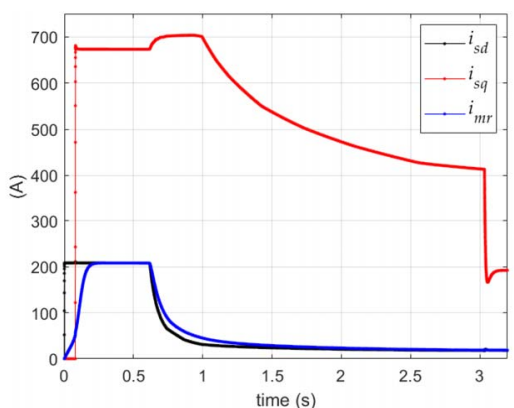

Fig. 12. $d-q$ and rotor magnetizing currents (zero to $20000 \mathrm{rpm}$ test)

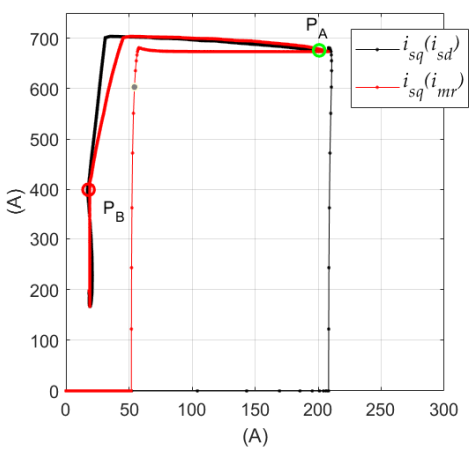

Fig. 13. Polar plot of the $d-q$ currents (zero to $20000 \mathrm{rpm}$ test) 
Fig. 14 shows the torque and power vs. speed behaviors, as they result from the control action, compared with the base and flux-weakening design points $\mathrm{P}_{\mathrm{A}}$ and $\mathrm{P}_{\mathrm{B}}$ achieved by FEM. The torque computed by the lumped parameter model is reduced by a factor of 0.91 (by experience) for this comparison, as the FEM computation uses a different calculation method (the virtual works method).

Finally, Figures 15 and 16 show the max acceleration from zero to $6000 \mathrm{rpm} / 104 \mathrm{Nm}$ operation, with the following activation of the "eco" driving mode on the MTPA curve.

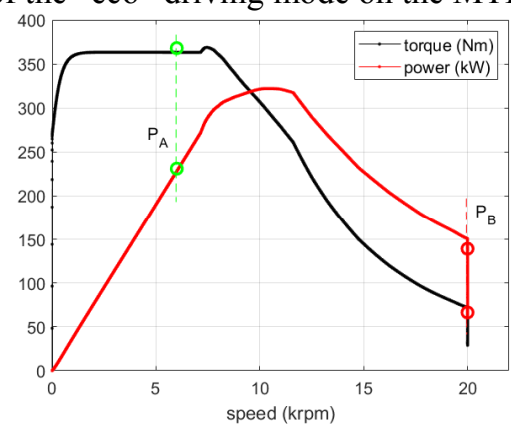

Fig. 14. Torque and power vs. speed capabilities (zero to $20000 \mathrm{rpm}$ test)

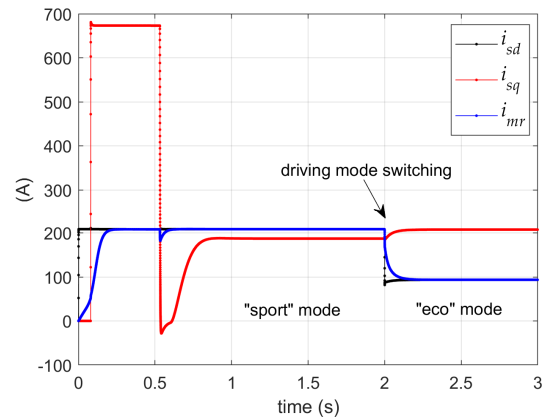

Fig. 15. $d-q$ and rotor magnetizing currents (zero to $6000 \mathrm{rpm}$ test)

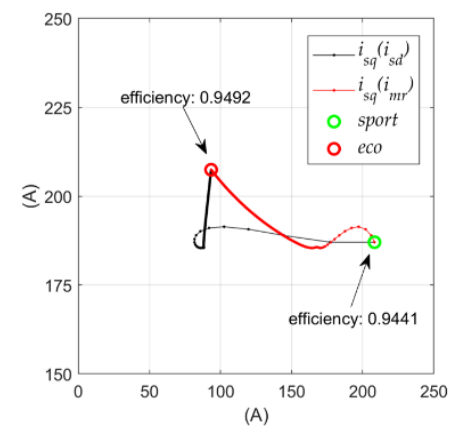

Fig. 16. Activation of the "eco" driving mode: polar plot of the $d-q$ currents, (zero to $6000 \mathrm{rpm}$ test, 1.5 to $3 \mathrm{~s}$ detail)

\section{CONCLUSIONS}

This paper shows focuses on a $200 \mathrm{~kW}$ induction motor drive designed for traction of a premium Battery Electric Vehicle. The study highlights the performance of the electric drive in the constant-torque and flux-weakening zones. Design features and data are provided. Then, the range from 6000 to $20000 \mathrm{rpm}$ is evaluated in terms of torque-speed capability by finite elements computations and dynamic simulations, and efficiency maps are provided. Field-oriented control strategies aiming to implement the driving modes of up-to-date electric vehicles are presented.

\section{ACKNOWLEDGMENT}

This project has received funding from the European Union's Horizon 2020 Research and Innovation Programme under the Grant Agreement No 770143.

\section{REFERENCES}

[1] V. Buyukdegirmenci, A. Bazzi, and P. Krein, "Evaluation of Induction and Permanent-Magnet Synchronous Machines Using Drive-Cycle Energy and Loss Minimization in Traction Applications," IEEE Trans. on Industry Applications, vol. 50, no. 1, pp. 395-403, 2014.

[2] J.F. Gieras and N. Bianchi, "Electric Motors for Light Traction," EPE Journal, vol. 14, no. 1, pp. 12-23, 2004.

[3] Z. Yang, F. Shang, I. Brown, and M. Krishnamurthy, "Comparative Study of Interior Permanent Magnet, Induction, and Switched Reluctance Motor Drives for EV and HEV Applications," IEEE Trans. on Transportation Electrification, vol. 1, no. 3, pp. 245-254, 2015.

[4] I. Boldea, L. Tutelea, L. Parsa, and D. Dorrell, "Automotive Electric Propulsion Systems With Reduced or No Permanent Magnets: An Overview," IEEE Trans. on Industrial Electronics, vol. 61, no. 10, pp. 5696-5711, 2014.

[5] M. Villani, M. Tursini, M. Popescu, G. Fabri, A. Credo, and L. Di Leonardo, "Experimental Comparison Between Induction and Synchronous Reluctance Motor-Drives," 2018 XIII Int. Conf. on Electrical Machines (ICEM), 2018.

[6] Credo, A., Fabri, G., Villani, M. and Popescu, M. (2019). High Speed Synchronous Reluctance Motors for Electric Vehicles: a Focus on Rotor Mechanical Design. 2019 IEEE International Electric Machines \& Drives Conference (IEMDC).

[7] D.G. Dorrell and A.F.F. Filho, "Design of torque-dense induction motors for automotive drive applications," IEEE Int. Symp. Ind. Electron., pp. 1446-1451, Sep. 2015.

[8] F. Briz, A. Diez, M. Degner, and R. Lorenz, "Current and flux regulation in field-weakening operation [of induction motors]," IEEE Trans. on Industry Applications, vol. 37, no. 1, pp. 42-50, 2001.

[9] S. Shaw and S. Leeb, "Identification of induction motor parameters from transient stator current measurements," IEEE Trans. on Industrial Electronics, vol. 46, no. 1, pp. 139-149, 1999.

[10] A. Del Gobbo, F. Parasiliti, and M. Tursini, "Microcontroller-Based On-Line Self-Tuning of the Rotor Time Constant for Field-Oriented Induction Motor Drives," Proc. of IEEE Int. Symp. on Industrial Electronics (ISIE), Guimaraes, Portugal, July 7-11, 1997, Vol. 3, pp. 1044-1049.

[11] M. Hachicha, N. Ben Hadj, M. Ghariani, and R. Neji, "Finite element method for induction machine parameters identification," First Int. Conf. on Renewable Energies and Vehicular Technology, 2012.

[12] ANSYS, Inc., "AC Motor Drive Using Cosimulation”, 2014, Application Brief, Web, 23 April 2019, https://www.ansys.com//media/ansys/corporate/resourcelibrary/techbrief/ab-ac-motor-driveusing-cosimulation.pdf.

[13] X. Zhao, H. Liu, Z. Zuo, H. Zhang, and Y. Chen, "Co-Simulation of $600 \mathrm{KW}$ Traction Induction Motor Fed by PWM Inverter," Proc. of the 2nd Int. Conf. on Electronic and Mechanical Engineering and Information Technology, 2012.

[14] L. Di Leonardo, F. Parasiliti, M. Tursini, and M. Villani, "Transient Analysis of PM Synchronous Motor Drives by Finite Element Model co-Simulation," Proc. of the $39^{\text {th }}$ Annual Conf. of the IEEE Industrial Electronics Society (IECON), Vienna, pp. 6834-6840, Nov. 2013.

[15] Riviere, N., Volpe, G., Villani, M., Fabri, G., Di Leonardo, L. and Popescu, M. (2019). Design Analysis of a High Speed Copper Rotor Induction Motor for a Traction Application. 2019 IEEE International Electric Machines \& Drives Conference (IEMDC).

[16] J. Goss, M. Popescu, and D. Staton, "A comparison of an interior permanent magnet and copper rotor induction motor in a hybrid electric vehicle application," Proc. of the Int. Electric Machines \& Drives Conference (IEMDC), 2013.

[17] D.W. Novotny and T.A. Lipo, Vector Control and Dynamics of AC Drives, New York:Oxford University Press Inc., 1996. 